\title{
Gliadin, zonulin and gut permeability: Effects on celiac and non-celiac intestinal mucosa and intestinal cell lines
}

\author{
Sandro Drago, Ramzi El Asmar, Mariarosaria Di Pierro, Maria Grazia \\ Clemente, Amit Tripathi Anna Sapone, Manjusha Thakar, Giuseppe Iacono, \\ Antonio Carroccio, Cinzia D'Agate, Tarcisio Not, Lucia Zampini, Carlo Catassi \\ \& Alessio Fasano MD
}

To cite this article: Sandro Drago, Ramzi El Asmar, Mariarosaria Di Pierro, Maria Grazia Clemente, Amit Tripathi Anna Sapone, Manjusha Thakar, Giuseppe lacono, Antonio Carroccio, Cinzia D'Agate, Tarcisio Not, Lucia Zampini, Carlo Catassi \& Alessio Fasano MD (2006) Gliadin, zonulin and gut permeability: Effects on celiac and non-celiac intestinal mucosa and intestinal cell lines, Scandinavian Journal of Gastroenterology, 41:4, 408-419, DOI: $10.1080 / 00365520500235334$

To link to this article: http://dx.doi.org/10.1080/00365520500235334

Published online: 26 Aug 2009.

Submit your article to this journal

Џlll Article views: 2637

Q View related articles $\sqsubset$

4 Citing articles: 22 View citing articles ๔ 


\title{
Gliadin, zonulin and gut permeability: Effects on celiac and non-celiac intestinal mucosa and intestinal cell lines
}

\author{
SANDRO DRAGO ${ }^{1,2}$, RAMZI EL ASMAR ${ }^{1}$, MARIAROSARIA DI PIERRO $^{1,2}$, \\ MARIA GRAZIA CLEMENTE ${ }^{1}$, AMIT TRIPATHI ${ }^{1}$, ANNA SAPONE ${ }^{1}$, \\ MANJUSHA THAKAR ${ }^{1}$, GIUSEPPE IACONO ${ }^{3}$, ANTONIO CARROCCIO $^{3}$, \\ CINZIA D'AGATE ${ }^{4}$, TARCISIO NOT ${ }^{5}$, LUCIA ZAMPINI ${ }^{6}$, CARLO CATASSI $^{1,6}$ \& \\ ALESSIO FASANO ${ }^{1}$
}

\begin{abstract}
${ }^{1}$ Mucosal Biology Research Center, Center for Celiac Research and Division of Pediatric Gastroenterology and Nutrition, University of Maryland, School of Medicine, Baltimore, USA, ${ }^{2}$ Bionat Italia S.r.l., Palermo, Italy, ${ }^{3}$ Clinica Medica, Policlinico Università di Palermo, Palermo, Italy, ${ }^{4}$ Azienda Ospedaliero Universitaria Policlinico-Univerita' degli Studi di Catania, Cattedra di Gastroenterologia, Catania, Italy, ${ }^{5}$ Clinica Pediatrica Universita' di Trieste and IRCCS Burlo Garofolo Trieste, Italy, and ${ }^{6}$ Dipartimento Scienze Materno-Infantile, Universita' Politecnico delle Marche, Ancona, Italy
\end{abstract}

\begin{abstract}
Objective. Little is known about the interaction of gliadin with intestinal epithelial cells and the mechanism(s) through which gliadin crosses the intestinal epithelial barrier. We investigated whether gliadin has any immediate effect on zonulin release and signaling. Material and methods. Both ex vivo human small intestines and intestinal cell monolayers were exposed to gliadin, and zonulin release and changes in paracellular permeability were monitored in the presence and absence of zonulin antagonism. Zonulin binding, cytoskeletal rearrangement, and zonula occludens-1 (ZO-1) redistribution were evaluated by immunofluorescence microscopy. Tight junction occludin and ZO-1 gene expression was evaluated by realtime polymerase chain reaction (PCR). Results. When exposed to gliadin, zonulin receptor-positive IEC6 and Caco2 cells released zonulin in the cell medium with subsequent zonulin binding to the cell surface, rearrangement of the cell cytoskeleton, loss of occludin-ZO1 protein-protein interaction, and increased monolayer permeability. Pretreatment with the zonulin antagonist FZI/0 blocked these changes without affecting zonulin release. When exposed to luminal gliadin, intestinal biopsies from celiac patients in remission expressed a sustained luminal zonulin release and increase in intestinal permeability that was blocked by FZI/0 pretreatment. Conversely, biopsies from non-celiac patients demonstrated a limited, transient zonulin release which was paralleled by an increase in intestinal permeability that never reached the level of permeability seen in celiac disease (CD) tissues. Chronic gliadin exposure caused down-regulation of both ZO-1 and occludin gene expression. Conclusions. Based on our results, we concluded that gliadin activates zonulin signaling irrespective of the genetic expression of autoimmunity, leading to increased intestinal permeability to macromolecules.
\end{abstract}

Key Words: Celiac disease, gliadin, gut permeability, tight junctions, zonulin

\section{Introduction}

Gliadin, the main fraction of wheat gluten responsible for the intestinal damage typical of celiac disease (CD), is the environmental factor that triggers this disorder [1]. It is known that CD is the result of an inappropriate T-cell-mediated immune response against ingested gliadin [2]. CD is associated with the HLA alleles DQA $1{ }^{\star} 0501 / \mathrm{DQB} 1{ }^{\star} 0201$, and in the continued presence of gliadin the disease is selfperpetuating [3]. One of the autoimmune targets of $\mathrm{CD}$ is tissue transglutaminase (TTG) [4]. The deamidating activity of this enzyme generates gliadin peptide fragments that bind to $\mathrm{DQ} 2$ and to $\mathrm{DQ} 8$ so as to be recognized by disease-specific intestinal $\mathrm{T}$ cells [5]. This process activates a cascade of events in which cytokines and matrix metalloproteinases are

Correspondence: Alessio Fasano, MD, Mucosal Biology Research Center, University of Maryland School of Medicine, 20 Penn Street, HSF II Building, Room 345, Baltimore, Md. 21201, USA. Tel: +1 410706 5501. Fax: +1 410706 5508. E-mail: afasano@mbrc.umaryland.edu 
up-regulated and the intestinal mucosa is destroyed $[6,7]$. CD is currently regarded as a paradigm of autoimmune disease for which the main genetic predisposition (HLA-DQ2/DQ8), the exogenous trigger (gluten), and one of the autoantigens (TTG) are known. In recent years much has been discovered about the genetic and immunologic aspects of CD [2]. However, little is known about the possible interactions of gliadin (and/or its peptide derivatives) with intestinal epithelia and the mechanism(s) through which it crosses the epithelial barrier to reach the submucosa. Under physiological circumstances, intestinal epithelia are almost impermeable to macromolecules such as gliadin [8]. Several studies reported that CD is a condition in which paracellular permeability is enhanced and the integrity of the tight junction ( $\mathrm{t} j$ ) system is compromised $[9,10]$. The up-regulation of zonulin, a recently described intestinal peptide involved in tj regulation [11], seems to be responsible, at least in part, for the increased gut permeability characteristic of CD [12]. Following stimulation of normal rat intestinal cells (IEC6) with gliadin, zonulin is released and induces a protein kinase C-mediated polymerization of intracellular actin filaments, which are directly connected to tj complex proteins, thereby regulating epithelial permeability [13]. Furthermore, the persistent presence of inflammatory mediators such as tumor necrosis factor- $\alpha(\mathrm{TNF}-\alpha)$ and interferon- $\gamma(\mathrm{INF}-\gamma)$ have been shown to increase the permeability across the endothelial and epithelial layers $[14,15]$.

The aim of this study was to investigate the early effects of gliadin on intestinal epithelial mucosa and the structures that dictate mucosal tj competency. Human intestinal specimens obtained from either treated $C D$ or non-CD subjects and intestinal epithelial cell lines were used. Our results provide evidence that gliadin activates the zonulin signaling, resulting in immediate reduction of intestinal barrier function and passage of gliadin into the subepithelial compartment. This process is dependent on the presence of the zonulin receptor but independent of individual genetic predisposition, suggesting that gliadin-induced, zonulin-mediated paracellular permeability could be required but is not sufficient to develop the autoimmune process typical of CD.

\section{Material and methods}

\section{Intestinal cell cultures}

Both human (Caco2 and T84) and rat-derived (IEC6) intestinal cells (passages 25-40) were cultured from frozen stocks. Dulbecco's Modified Eagle Medium (D-MEM; Gibco, Grand Island, NY, USA) containing $4500 \mathrm{mg} / 1 \mathrm{D}$-glucose and pyridoxine hydrochloride was supplemented with $5 \%$ heat inactivated $\left(56^{\circ} \mathrm{C}, 30 \mathrm{~min}\right)$ fetal bovine serum (FBS), $0.1 \mathrm{U} / \mathrm{ml}$ bovine insulin, $4 \mathrm{mM} \mathrm{L}$-glutamine, $100 \mathrm{U} / \mathrm{ml}$ penicillin and $100 \mu \mathrm{g} / \mathrm{ml}$ streptomycin for IEC-6-cell propagation, or supplemented with $10 \%$ heat inactivated FBS, $0.1 \mathrm{mM}$ non-essential amino acids, $1.0 \mathrm{mM}$ sodium pyruvate, $2 \mathrm{mM} \mathrm{L}$-glutamine, $2.5 \mu \mathrm{g} / \mathrm{ml}$ amphotericin $\mathrm{B}, 50 \mathrm{U} / \mathrm{ml}$ penicillin and $50 \mu \mathrm{g} / \mathrm{ml}$ streptomycin for Caco2 cell propagation. A 1:1 mixture of DMEM and Ham's F12 medium (D-MEM/F-12; Life Technologies) containing $15 \mathrm{mM}$ HEPES, $2.5 \mathrm{mM}$ L-glutamine and $0.5 \mathrm{mM}$ sodium pyruvate was supplemented with $10 \%$ heat inactivated FBS, $100 \mathrm{U} / \mathrm{ml}$ penicillin and $100 \mu \mathrm{g} / \mathrm{ml}$ streptomycin for T84-cell propagation. Cells were cultured in a $5 \% \quad \mathrm{CO}_{2}$ atmosphere at $37^{\circ} \mathrm{C}$ into 6 -well tissue culture plates. For the immunofluorescence experiments, cells were grown to sub-confluence (non-polarized), while for the $\mathrm{Caco} 2$ monolayer, experimental cells were grown to confluence, followed by additional 10 days of growth to allow cell differentiation.

\section{Subcellular fractionation}

Cells were grown in $175 \mathrm{~cm}^{3}$ culture flasks until $>90 \%$ confluence was reached. An enzymefree solution (Gibco, Grand Island, NY, USA) was used to detach the cells. After centrifugation for $5 \mathrm{~min}$ at $1000 \mathrm{rpm}+4^{\circ} \mathrm{C}$, the medium was discharged, cells were resuspended in $0.25 \mathrm{M}$ sucrose- $20 \mathrm{mM}$ Tris- $\mathrm{Cl}$ solution and homogenized by passing 15 times through a G-25 needle. The homogenate was first centrifuged for $15 \mathrm{~min}$ at $1000 \mathrm{~g}$ to separate nuclei, plasma membrane sheets, and cell debris (pellet); the supernatant obtained was then centrifuged for $15 \mathrm{~min}$ at $10,000 \mathrm{~g}$ to separate mitochondria, lysosomes, peroxisomes (pellet); the remaining supernatant was finally ultracentrifuged for $1 \mathrm{~h}$ at $100,000 \mathrm{~g}$ to separate all vesicles from endoplasmic reticulum and Golgi (pellet) from the soluble cytosolic protein fraction (supernatant).

\section{Gliadin and casein digests}

Gliadin was digested as previously described $[16,17]$ with minor modifications. Briefly, $50 \mathrm{~g}$ gliadin (crude-wheat-Sigma, St. Louis, Mo., USA) was dissolved in $500 \mathrm{ml} 0.2 \mathrm{~N} \mathrm{HCl}$ for $2 \mathrm{~h}$ at $37^{\circ} \mathrm{C}$ with $1 \mathrm{~g}$ pepsin (Sigma). The resultant peptic digest was further digested by addition of $1 \mathrm{~g}$ trypsin (Sigma) after $\mathrm{pH}$ adjusted to 7.4 using $\mathrm{NaOH} 2 \mathrm{M}$. The solution was stirred vigorously at $37^{\circ} \mathrm{C}$ for $4 \mathrm{~h}$, and then boiled $\left(100^{\circ} \mathrm{C}\right)$ for $30 \mathrm{~min}$, freeze-dried, lyophilized in $10 \mathrm{mg}$ batches, and stored at $-20^{\circ} \mathrm{C}$ 
until used. Pepsin-trypsin digested gliadin (PTgliadin) was freshly prepared by suspending it in PBS to a final concentration of $1 \mathrm{mg} / \mathrm{ml}$. Pancreatic digested (PD)-casein (BactoTryptone, Becton Dickenson, Sparks, Md., USA) was used as a negative control in all the experiments performed.

\section{Synthesis of the zonulin peptide inhibitor FZI/O}

The zonulin synthetic peptide inhibitor FZI/0, which is capable of competitively blocking the zonulin receptor and the consequent zonulin-dependent opening of the ti, was identified and prepared as previously described in structure-function analysis studies of the Zot/zonulin receptor binding motif [18] and was obtained from the Biopolymer Laboratories, University of Maryland, Baltimore, USA.

\section{Immunofluorescence microscopy on intestinal cell lines}

Cells were washed in phosphate buffered saline (PBS) and gently detached by exposure to $0.25 \%$ trypsin, $1 \mathrm{mM}$ EDTA solution (Gibco brl) for 2$3 \mathrm{~min}$. The cells $\left(2 \times 10^{4}\right.$ cells $\left./ \mathrm{ml}\right)$ were suspended in medium and seeded onto 8 chamber slides (Nalge Nunc International, Naperville, IL, USA). At a cell confluence of $60-70 \%$ PT-gliadin $(1 \mathrm{mg} / \mathrm{ml})$ was added for $30 \mathrm{~min}$ of incubation at $37^{\circ} \mathrm{C}$ in $5 \% \mathrm{CO}_{2}$ atmosphere. Cells were then washed twice in PBS, fixed in $3.7 \%$ paraformaldeyde in PBS ( $\mathrm{pH} \mathrm{7.4)} \mathrm{for}$ $15 \mathrm{~min}$ at room temperature. To analyze intracellular F-actin, cells were permeabilized with $0.5 \%$ TritonX-100 in PBS (Sigma) for $10 \mathrm{~min}$ at room temperature and incubated for $30 \mathrm{~min}$ with $0.3 \mu \mathrm{M}$ solution of FITC-phalloidin (SIGMA). To study zonulin surface binding, cells were incubated with zonulin-specific anti-Zonula occludens toxin (Zot) $\Delta \mathrm{G}$ antibodies $(10 \mu \mathrm{g} / \mathrm{ml})$ [18] for $1 \mathrm{~h} \mathrm{at} \mathrm{room}$ temperature without permeabilization, washed 3 times in PBS and than incubated for $30 \mathrm{~min}$ at room temperature with the anti-rabbit FITC-conjugated antiserum (SIGMA). After 3 additional washes, the cover slips were mounted with glycerol-PBS (1:1) at $\mathrm{pH}$ 8.0. The results were blindly analyzed by two independent observers using a fluorescence microscope (Zeiss) and images taken with a digital camera (Nikon).

\section{Immunofluorescence microscopy on intestinal tissues}

These experiments were performed as previously described [19]. Briefly, small-bowel biopsies obtained by endoscopy were freshly embedded in OCT compound and stored at $-80^{\circ} \mathrm{C}$. Cryosections of 5-7 $\mu \mathrm{m}$ were incubated with zonulin-specific, polyclonal anti-Zot antibodies, extensively washed, and incubated with fluorescein isothiocya- nate (FITC)-conjugated goat anti-rabbit antibody (Sigma) in the dark. After repeated washing, the tissue sections were mounted on slides with mounting medium and blindly examined under fluorescence microscopy.

\section{Direct immunofluorescence and ZO1 localization migration in intestinal cell monolayers}

Intestinal cells were grown on 8-chamber slides using the growth conditions outlined above and incubated with either PT-gliadin or the negative control PT-casein (final concentration $1 \mathrm{mg} / \mathrm{ml}$ ) at increasing time intervals. PBS-exposed monolayers were used as additional controls. Cells were then washed gently with PBS and permeated with methanol at $-20^{\circ} \mathrm{C}$ for $2 \mathrm{~min}$. The monolayers were then washed three times with PBS, and incubated with primary antibodies (FITC-conjugated anti-ZO1 monoclonal antibody; Zymed Laboratories Inc., San Francisco, Calif., USA). After $60 \mathrm{~min}$ of incubation, the slides were washed twice with PBS, air-dried, and blindly analyzed by fluorescence microscopy.

\section{Caco2 monolayers experiments}

Culture conditions. Caco2 cells (passage 25-40) were grown on filter clusters until confluence (average 10-15 days post-seeding); $200 \mu \mathrm{l}$ DMEM was added to the mucosal (apical) side and $3 \mathrm{ml}$ of the same medium was added to the serosal (basolateral) side. The system was incubated at $37^{\circ} \mathrm{C}$ in an atmosphere of $95 \%$ air and $5 \% \mathrm{CO}_{2}$. The culture medium was changed every third day. The monolayer was washed with PBS twice and incubated with DMEM supplemented as above but without antibiotics. Replicates of Caco2 monolayers were incubated at increasing time intervals with either $1 \mathrm{mg} / \mathrm{ml}$ PT-gliadin or $1 \mathrm{mg} / \mathrm{ml}$ PD-casein, used as control. Both preparations were added to the mucosal (apical) side of the Caco2 monolayers. Medium samples for each compartment were obtained to test for zonulin release and passage of lactulose.

Transepithelial electrical resistance (TEER) measurements. The baseline TEER of Caco 2 monolayers grown on filter clusters was measured using a dual planar electrode (Endhom SNAP Evom G WPI analyzer; World Precision Instruments) and expressed in $\Omega . \mathrm{cm}^{2}$. TEER values were measured for each incubation time after the addition of PT-gliadin and PD-casein and corrected for the baseline resistance values. 
Measurement of lactulose flux from the apical to basolateral side of Caco2 monolayers. Lactulose, a probe used to check paracellular permeability, was added at $40 \mathrm{mM} / \mathrm{ml}$ final concentration to the apical side of all monolayers at time 0 . Samples were collected from the basolateral side at increasing time intervals and lactulose concentration measured by high performance anion exchange chromatography (HPAEC). After deproteination with acetonitrile $1: 1 \mathrm{v} / \mathrm{v}$, samples were centrifuged at $4000 \mathrm{rpm}$ for $10 \mathrm{~min}$, the supernatant collected, filtered through a $0.22 \mu \mathrm{m}$ membrane (Millipore, Bedford, Mass., USA), and diluted with water 1 to 10 (basolateral samples) or 1 to 100 (apical samples). For HPAEC analysis we used an HPAEC-PAD system (Pulsed Amperometric Detector) 4500 Dionex, comprising a CarboPac PA-1 column $(4 \times$ $250 \mathrm{~mm}$ ) (Dionex), in serial with a precolumn CarboPac PA-1 Guard $(3 \times 25 \mathrm{~mm})$ (Dionex); a pulsed amperometric detector (PAD II) connected by a gold electrode.

\section{Intestinal tissue from $C D$ and non-CD patients}

Samples of small-intestine mucosa were taken from the second/third portion of the duodenum from subjects undergoing upper gastrointestinal (GI) endoscopy. Patients included: 1) subjects with active $\mathrm{CD}$ at diagnosis; 2) subjects with $\mathrm{CD}$ on treatment with a gluten-free diet for at least 2 years, and 3) non-CD GI controls with persistent dyspeptic complaints. All patients had clinical indications for the procedure and gave their informed consent to undergo an additional biopsy for the purpose of this study. The study protocol was approved by the Ethics Committee of the University of Ancona. The small-intestine biopsies were oriented under a dissecting microscope $(16 \times)$ with the villi facing upward and mounted onto the modified microsnapwell system [20]. The study was then conducted as described above for the $\mathrm{Caco} 2$ monolayers experiments.

\section{Zonulin determination by sandwich enzyme-linked immunosorbent assay (ELISA)}

Zonulin content from either cell cultures (both cell culture media and subcellular protein fractions) or intestinal segments mounted in the microsnapwell system was quantified using a sandwich ELISA as previously described [20].

\section{Quantitative polymerase chain reaction with the TaqMan procedure}

To analyze the effect of both acute and prolonged intestinal exposure to gliadin on tj structural ele- ments, occludin and ZO-1 genes expression was analyzed by real-time PCR [21]. Cytokine TNF- $\alpha$ gene expression was also determined using the same technology. Total tissue RNA was extracted (QiAamp RNA Blood Mini Kit; QIAGEN Inc., Valencia, Calif., USA) from each intestinal fragment (from both $\mathrm{CD}$ and non-CD subjects) mounted in the microsnapwell system. In order to eliminate any DNA traces, the RNA obtained was treated with deoxyribonuclease I, amplication grade, according to the manufacturer's instructions (Invitrogen Carlsbad, Calif., USA) and the reverse transcription of RNA to cDNA was performed using GeneAmp RNA PCR kit components (Perkin Elmer Applied Biosystems, Forster City, Calif., USA). The cycling protocol consisted of $42^{\circ} \mathrm{C} 15 \mathrm{~min}, 99^{\circ} \mathrm{C}$ $5 \mathrm{~min}$. To quantify the occludin and ZO-1 RNA level, primers (ZO-1: Forward: 5'-TTAAGCCAGCCTCTCAACAGAAA, Reverse: 5'-GGT TGA TGA TGC TGG GTT TGT. Occludin: Forward: 5'- TAT AAA TCC ACG CCG GTT CCT, Reverse: 5'- ACG AGG CTG CCT GAA GTC AT) and probe (ZO-1: 6FAM- ATC TCC AGT CCC TTA CCT TTC GCC TGA ATAMRA. Occludin: 6FAM- AAG TGG TTC AGG AGC TTC CAT TAA CTT CGC-TAMRA) was designed (PRIMER EXPRESS software Perkin Elmer Biosystems) and used in a multiplex real-time PCR assay. Primers and probe were obtained from Oligo Synthesis Group from Applied Biosystems. For each PCR reaction a primers pair and probe (VIC Probe) amplifying the human GAPDH was used as an internal positive control (IPC) (TaqMan ${ }^{\circledR}$ RNA Control Reagents; Perkin Elmer Applied Biosystems). To analyze the TNF- $\alpha$ expression, the cDNA was amplified by using Pre-Developed TaqMan Assay Reagents $(20 \times$, Perkin Elmer Applied Biosystems).

PCR reagents consisted of TaqMan Universal PCR Master Mix $(50 \mathrm{mM} \mathrm{KCl}, 10 \mathrm{mM}$ Tris- $\mathrm{HCl}$, $0.01 \mathrm{M}$ EDTA, $60 \mathrm{nM}$ Passive Reference, $\mathrm{pH} 8.3$ at room temperature, $3.5 \mathrm{mM} \mathrm{MgCl} 2,200 \mu \mathrm{M}$ dATP, $200 \mu \mathrm{M}$ dCTP, $200 \mu \mathrm{M}$ dGTP, $400 \mu \mathrm{M}$ dUTP, $0025 \mathrm{U} / \mu \mathrm{L}$ AmpliTaq Gold, 0.01 U/ $\mu 1$ AmperaseUNG), forward primers $0.6 \mu \mathrm{M}$, reverse primers $0.6 \mu \mathrm{M}$ TaqMan probes $0.2 \mu \mathrm{M}, 5 \mu \mathrm{l}$ of target cDNA and DEPC water up to $50 \mu \mathrm{l}$ final volume. Cycle parameters were $50^{\circ} \mathrm{C}$ for $10 \mathrm{~min}$ (1 cycle), $95^{\circ} \mathrm{C}$ for $10 \mathrm{~min}(1 \mathrm{cycle}), 95^{\circ} \mathrm{C}$ for $30 \mathrm{~s}-60^{\circ} \mathrm{C}$ for $1 \mathrm{~min}$ (40 cycles). (ABI Prism 7700 Sequence Detection System; Perkin Elmer Applied BioSystems). The target cDNA in duplicate and plasmid DNA (prRNA18S) as standard DNA were included in a single 96-well plate. 


\section{S. Drago et al.}

\section{Construction of standard plasmid DNA}

In order to quantify occludin, $\mathrm{ZO}-1$ and $\mathrm{TNF} \alpha$ mRNA levels we constructed a recombinant plasmid to produce a standard DNA molecule (prGAPDH). Briefly, the cDNA encoding human GAPDH gene was amplified by PCR from a cDNA template derived from human intestine; the amplicon obtained was analyzed using agarose gel electrophoresis $(2 \%)$. Finally, the PCR product was cloned into the PCR ${ }^{\circledR} 2.1-$ TOPO $^{\circledR}$ vector, as recommended by the manufacturer (TOPO TA Cloning Kit; Invitrogen). Ten-fold dilutions from $10 \mathrm{ng} /$ reaction to $1 \mathrm{fg} /$ reaction were used in TaqMan procedures as standard DNA.

\section{Statistical analysis}

All values are expressed as means \pm SE (standard error). The analysis of differences was performed by $t$-test for either paired or unpaired varieties. A $p$ value $<0.05$ was considered statistically significant.

\section{Results}

\section{Experiments on intestinal cell lines}

Effect of PT-gliadin on zonulin release, actin cytoskeleton, and surface binding in intestinal epithelial cells. Human intestinal epithelial cells Caco2 and T84 as well as rat small-intestine IEC6 cells exposed to PT-gliadin showed zonulin release in the culture medium, irrespective of the cell line challenged (Figure 1A). Conversely, only zonulin receptor-positive IEC6 and Caco2 cells [22] showed zonulin surface immunostaining, while no signal was detectable in zonulin receptor-negative T84 cells (Figure 1B). Caco2 cell subfractionation revealed that the endoplasmic reticulum/Golgi fraction was the most enriched in zonulin content $(1.14 \pm 0.03 \mathrm{ng} / \mathrm{mg}$ protein) as compared with the plasma membrane $(0.05 \pm 0.07 \mathrm{ng} / \mathrm{mg}$ protein $)$, cytoplasm $(0.28 \pm 0.08 \mathrm{ng} / \mathrm{mg}$ protein), and mitochondria $(0.16 \pm 0.14 \mathrm{ng} / \mathrm{mg}$ protein) fractions. We have already reported that zonulin binding in IEC6 cells was associated with an early reorganization of intracellular actin filaments characterized by a redistribution of F-actin to the cell subcortical compartment [13]. Here, we report similar results obtained in Caco2 cells (Figure 2), whereas no significant changes were observed in T84 cells (Figure 2) in which the zonulin release (Figure 1A) was not followed by its binding to the cell surface (Figure 1B). Two hours after gliadin withdrawal, the reorganization of the actin cytoskeleton recovered, and the cytoskeleton had returned to its basal state (data not shown).
A
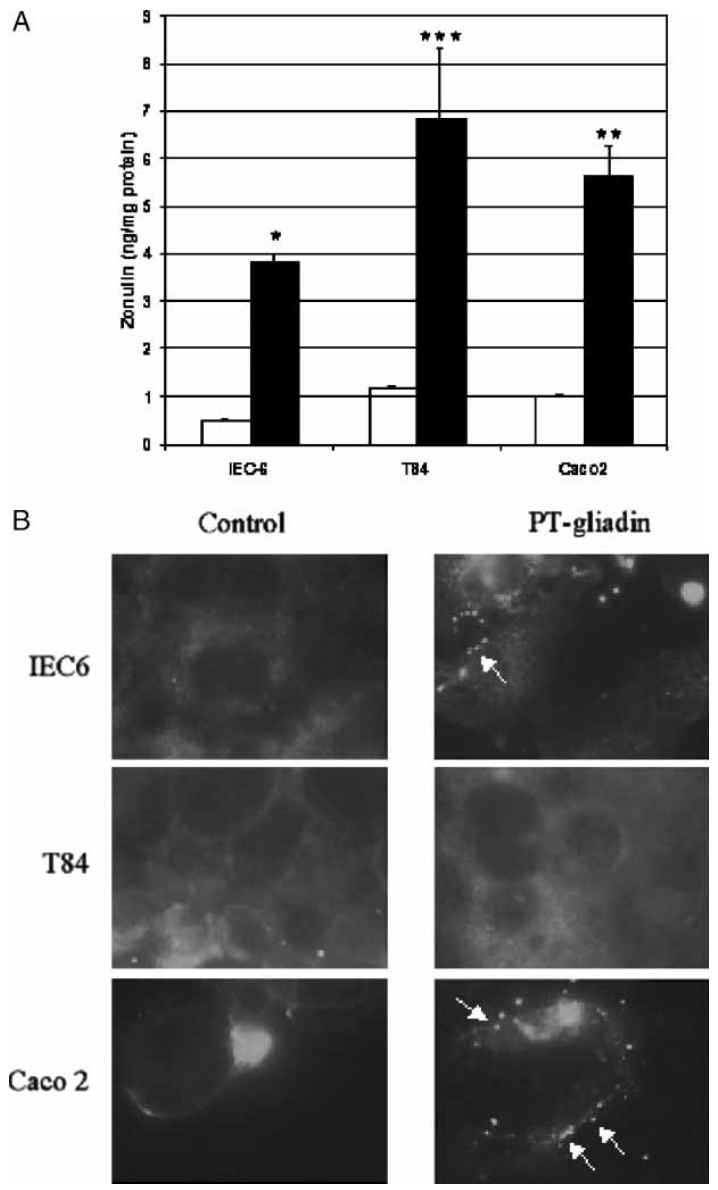

Figure 1. Zonulin release and surface binding in intestinal epithelial cell cultures following gliadin exposure. A. Zonulin release was detected in the medium of PT-gliadin-exposed cells (closed bars) but not in PD-casein-exposed cells (open bars). B. Immunofluorescence analysis also revealed that this release was associated with zonulin binding on the surface of zonulin receptorpositive Caco2 and IEC6 cells (see arrows) but not zonulin receptor-negative T84 cells. Magnification: $\times 40 ; n=4-8$; ${ }^{\star} p<0.0001 ;{ }^{\star \star} p<0.003 ;{ }^{\star \star \star} p<0.009$.

Direct immunofluorescence microscopy of ZO-1 localization on intestinal cell monolayers exposed to PTgliadin. ZO-1 is one of the best-characterized components of the junctional complex and it localizes in the cytoplasmic submembranous plaque underlying intercellular tj. Its presence at the cell boundary is considered a sign of tj competency [23]. Immunofluorescence analysis of both Caco 2 and IEC6 cells was used to establish whether the zonulin release and actin rearrangement following PT-gliadin exposure could affect the distribution of ZO-1. Casein was used as a food-derived protein negative control. Both untreated Caco2 monolayers and PD-caseinexposed $\mathrm{Caco} 2$ monolayers showed the typical ZO1 localization at the cell periphery $90 \mathrm{~min}$ postincubation (Figure 3). Conversely, PT-gliadinexposed cells showed a fluorescent irregular pattern at the edge of the cells due to a redistribution of the 

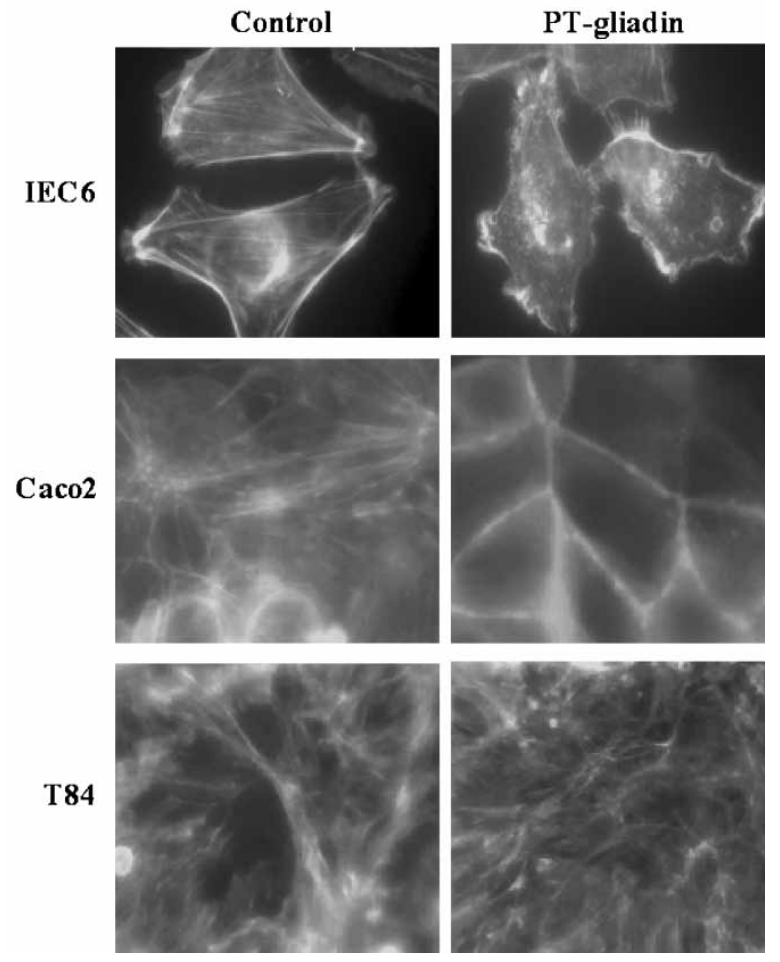

Figure 2. Effect of gliadin on intestinal epithelial cells cytoskeleton. Incubation of both Caco2 and IEC6 cells with PT-gliadin leads to a reorganization of actin filaments characterized by their redistribution to the cell subcortical compartment. F-actin fluorescence pattern remains unchanged in T84 cells exposed to PT-gliadin. Magnification: $\times 40$.

ZO1 protein, (Figure 3). Reciprocal co-immunoprecipitation experiments showed a time-dependent disassociation between $\mathrm{ZO}-1$ and occludin (data not shown) that, combined with the immunofluorescence results, is suggestive of ti disassembly [24].

Effect of PT-gliadin on Caco2 monolayers barrier function. The addition of PT-gliadin to the mucosal aspect of $\mathrm{Caco} 2$ monolayers induced a significant decrease in TEER, while no changes were detected in monolayers challenged with PD-casein (Figure 4A). The loss of barrier function was preceded by a significant luminal (but not basolateral) secretion of zonulin from cells incubated with PT-gliadin (Figure 4B). No detectable zonulin was found in monolayers exposed to PD-casein (Figure 4B). To confirm that the zonulin-mediated TEER decrease involved the opening of intercellular t $\mathrm{j}$, the mucosal-to-serosal transport of the paracellular marker lactulose was also monitored. In monolayers challenged with PT-gliadin, an increase in serosal lactulose $(0.080 \pm 0.03 \mu \mathrm{g} / \mathrm{ml})$ was observed $90 \mathrm{~min}$ after PT-gliadin exposure compared to untreated monolayers $(0.025 \pm 0.005, \mathrm{~N}=7, p<0.01$ compared to PT-gliadin-treated monolayers). Pretreatment with the competitive zonulin antagonist FZI/0 prevented the increased paracellular lactulose transport $(0.02 \pm 0.02)$, further supporting the hypothesis that the PT-gliadin-induced changes in TEER and paracellular permeability are zonulin dependent.

\section{Experiments on human intestinal tissues}

Zonulin release and TEER changes in human intestinal tissues of $C D$ patients in remission and non-CD patients exposed to PT-gliadin. In addition to the up-regulation of zonulin in acute CD, we have previously reported that gliadin activates the zonulin-signaling pathway even when added to normal rabbit intestinal epithelium [13]. Based on these results, we studied the effect of PT-gliadin on the zonulin signaling ex vivo by using human duodenal biopsies obtained during routine diagnostic endoscopies from both $\mathrm{CD}$ patients in remission and non-CD subjects. The tissues were mounted in the microsnapwell system [20] immediately after their collection and zonulin release and TEER were monitored both at baseline and following exposure to either PT-gliadin or negative control. At baseline, the zonulin concentration in tissue culture media collected from the luminal side of biopsies from CD patients
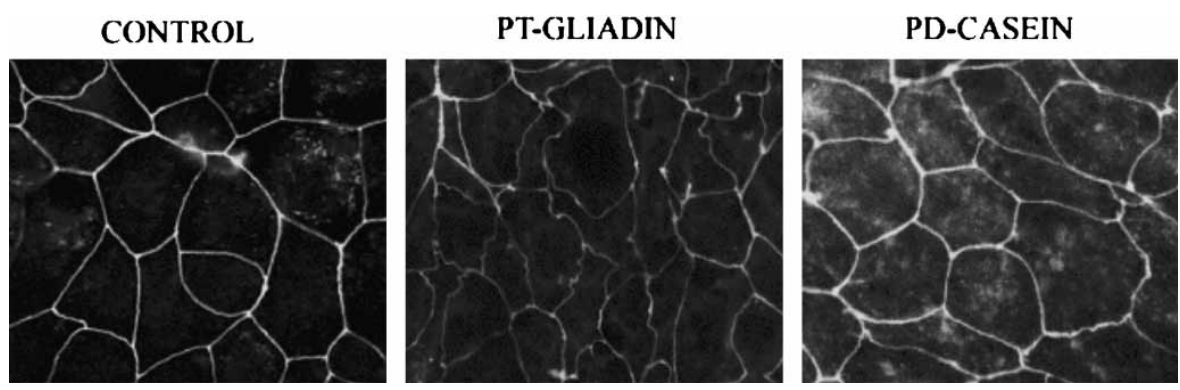

Figure 3. Effects of PT-gliadin on the junctional complex protein ZO-1 localization in Caco2 cells. Human intestinal Caco2 cells were exposed to PT-gliadin, fixed after 90 min post-incubation, and immunostained using anti-ZO1 antibodies. Control monolayers show the typical ZO-1 localization at the periphery of the cells. Monolayers exposed to PT-gliadin show different degrees of ZO-1 redistribution, with areas with reduced or loss of ZO-1 staining at the edge of the cell and areas in which no significant changes were detected. No changes in ZO-1 localization were detected in monolayers exposed to PD-casein. 

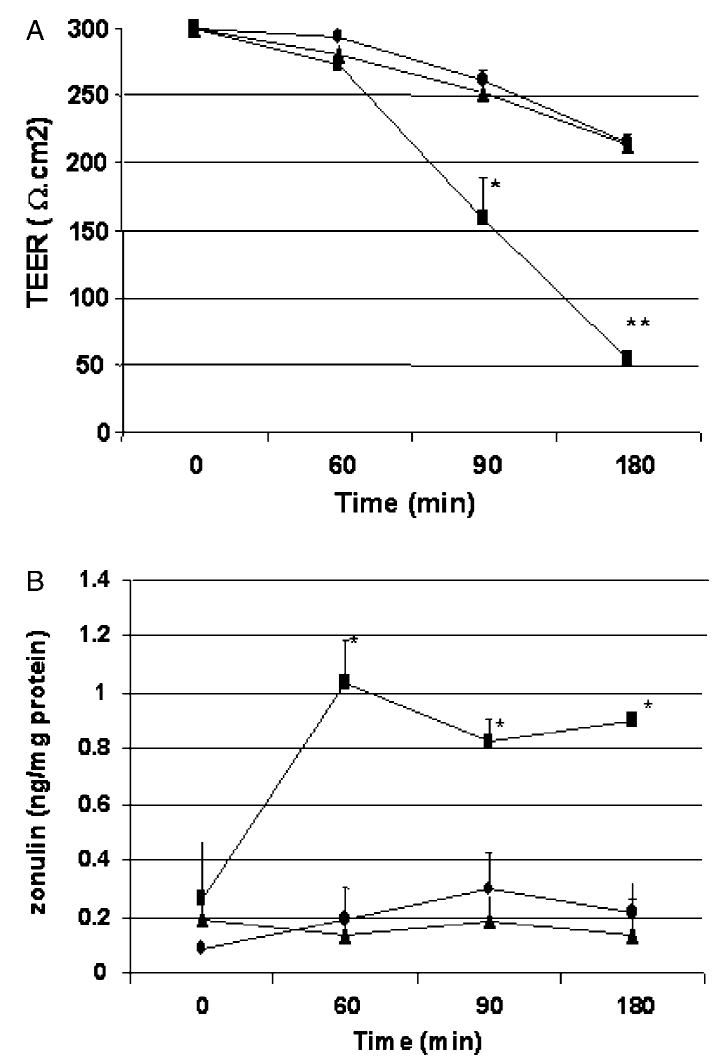

Figure 4. Transepithelial electrical resistance (TEER) and zonulin secretion changes in $\mathrm{Caco} 2$ monolayers exposed to PT-gliadin. A. Monolayers exposed to PT-gliadin (squares) show significant TEER decrease $\left({ }^{\star} p<0.01 ;{ }^{\star \star} p<0.005\right)$ starting 90 min postincubation compared to both media control monolayers (circles) and PT-casein-exposed monolayers (triangles). B. Kinetics of zonulin release from $\mathrm{Caco} 2$ monolayers exposed to media control (circles), inoculated with PT-gliadin (squares), or casein (triangles). PT-gliadin-exposed monolayers show a significantly higher zonulin release starting $60 \mathrm{~min}$ post-incubation compared to both control and PD-casein-challenged monolayers $\left({ }^{\star} p<0.01\right.$; $\left.{ }^{\star \star} p<0.005\right) ; n=3-5$ determinations.

$(0.67 \pm 0.13 \mathrm{ng} / \mathrm{mg}$ protein) was greater than that from non-CD controls $(0.02 \pm 0.01, p<0.01)$. This baseline zonulin up-regulation was paralleled by a lower baseline TEER in tissues obtained from CD patients in remission $\left(40 \pm 8.5 \Omega \mathrm{cm}^{2}\right)$ as compared to tissues obtained from non-CD patients $(133 \pm 12.8, p<0.001)$ (see below). Following PTgliadin exposure, two different responses were observed. Tissue from CD patients showed a sustained zonulin release into the mucosal (but not serosal) medium that was higher than the baseline levels, beginning as early as $5 \mathrm{~min}$ post-incubation (Figure 5A) and persisting for $\geq 1 \mathrm{~h}$. Conversely, biopsies from non-CD patients exhibited transient increases in luminal but not serosal zonulin levels that peaked at $15 \mathrm{~min}$ and returned to baseline within $30 \mathrm{~min}$ (Figure 5A). The zonulin release in both groups was temporally associated with the observed changes in TEER (Figure 5B). While the
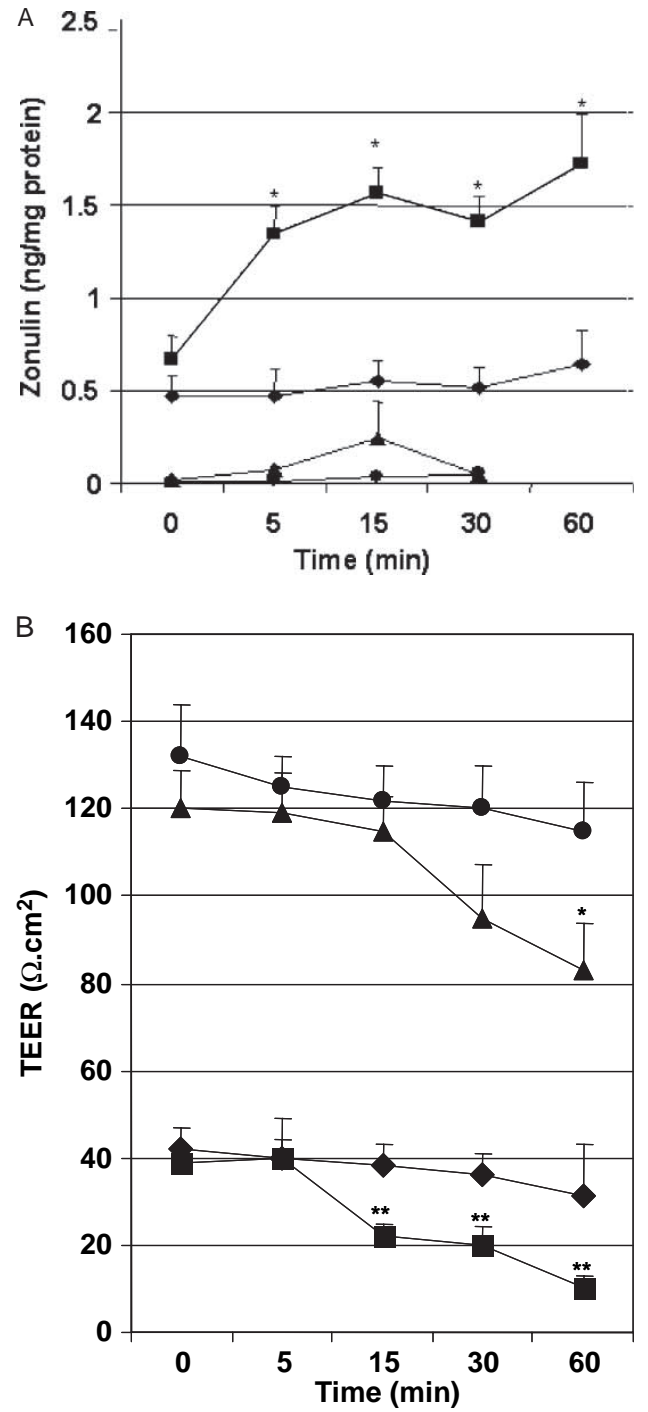

Figure 5. Zonulin release and transepithelial electrical resistance (TEER) changes in intestinal biopsies obtained from celiac disease (CD) patients in remission and non-CD patients exposed to PT-gliadin. Intestinal duodenal biopsies were mounted in microsnapwell chambers and polarized zonulin release and changes in TEER monitored. A. Zonulin release. Following exposure to PT-gliadin, tissues obtained from CD patients showed a luminal (squares) but not serosal (diamonds) zonulin release. Conversely, biopsies from non-CD patients showed a transitory zonulin release in the mucosal (triangles) but not serosal (circles) media that reached its peak at $15 \mathrm{~min}$ post-PT-gliadin incubation and returned to baseline within 30 min. ${ }^{\star} p<0.005$ compared to serosal zonulin $n=17 \mathrm{CD}$ patients and $n=5$ non-CD controls. B. TEER changes. Tissues obtained from both $C D$ patients in remission and non-CD controls showed a TEER decrement temporally associated with zonulin release. In CD tissues, a significant drop in TEER compared to baseline was observed starting $15 \mathrm{~min}$ post-PT-gliadin incubation (squares). No significant changes were detected in negative controls exposed tissues (diamonds). Conversely, in tissues from non-CD patients, a significant decrease in TEER was observed only after $60 \mathrm{~min}$ post-PT-gliadin incubation (triangles). Again, no changes were detected in tissues exposed to negative controls (circles). ${ }^{\star} p<0.05 ;{ }^{\star \star} p<0.001$ compared to respective negative controls; $n=17 \mathrm{CD}$ patients and $n=5$ non-CD controls. 
TEER decrease in tissues obtained from CD patients reached significance $15 \mathrm{~min}$ following PT-gliadin exposure, the TEER changes in tissues from nonCD subjects did not reach statistical significance until 60 min after PT-gliadin incubation (Figure 5B). The TEER of CD patient-derived tissues was always lower than the TEER of non-CD tissues, irrespective of gliadin exposure and time of incubation (Figure 5B). No significant changes were detected in either group when tissues were exposed to the negative control (Figure 5B).

Effect of the zonulin inhibitor FZI/O on TEER changes. To establish whether the PT-gliadin-induced zonulin release and TEER changes were causally related, intestinal biopsies obtained from CD patients in remission were pretreated with the zonulin inhibitor FZI/0 prior to PT-gliadin exposure. Tissue preincubation for $15 \mathrm{~min}$ with FZI/0 did not affect zonulin release (Figure 6B) but did prevent the drop in PT-gliadin-induced TEER (Figure 6A). These results provide direct evidence that the gliadin-induced TEER changes are zonulin dependent.

Zonulin binding to human intestinal tissues following exposure to PT-gliadin. To establish whether PTgliadin-induced zonulin release was followed by zonulin binding to the intestinal epithelium (as observed in intestinal cell lines, see above), in situ immunofluorescence microscopy studies using zonulin-specific anti-Zot antibodies were performed. Tissues obtained from CD patients in remission and exposed to PT-gliadin showed a homogeneous staining on the mucosal surface (Figure 7A), while no zonulin binding was detected on tissues exposed to negative controls (Figure 7B). Tissues from non-CD patients exposed to PT-gliadin also showed mucosal surface staining; however, the zonulin binding appeared patchy (Figure 7C), suggesting less binding to its surface receptor.

Effect of both acute and chronic exposure to gliadin on ZO1 and occludin gene expression. Occludin and ZO-1 are considered key elements on the tj complex and their expression and localization dictate tj competency. To establish whether the TEER changes induced by PT-gliadin were associated with modification in tj occludin and ZO-1 expression, RNA levels of the two proteins were quantified by realtime $\mathrm{PCR}^{21}$ following both acute (ex vivo) and chronic (in vivo) exposure to gliadin.
Acute exposure. Human intestinal tissues mounted in the microsnapwell assay (see above) were harvested at increasing time intervals, mRNA extracted and both $\mathrm{ZO}-1$, and occludin quantitative expression measured by real-time PCR. Tissues obtained from CD patients in remission and exposed to PT-gliadin showed a progressive decrement in occludin but not ZO-1 gene expression up to 60 min post-incubation (Table I). Tissue from non-CD patients and exposed to PT-gliadin also showed a decrement in occludin genes expression, but the reduction was less pronounced as compared with that seen in CD patients (Table I). No significant changes in TNF- $\alpha$ gene expression were detected in both groups, further supporting our previous observation that the TEER
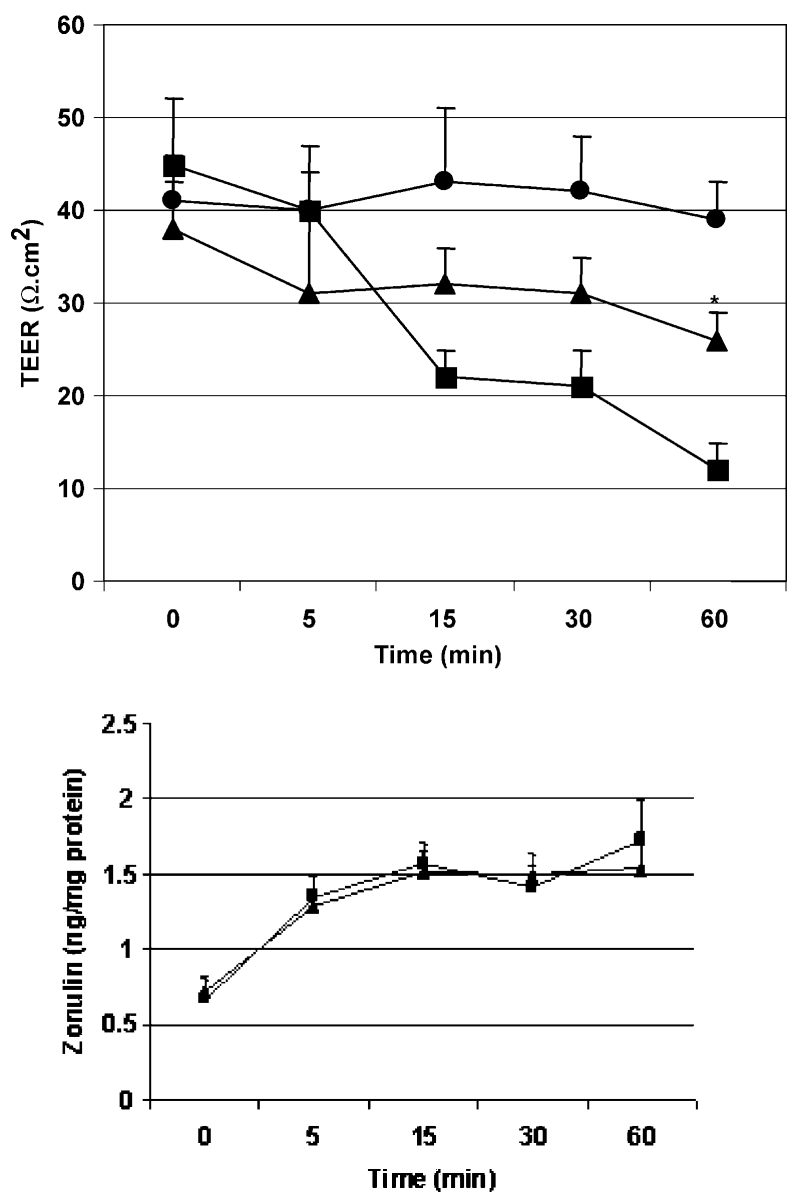

Figure 6. Effect of the zonulin inhibitor FZI/0 on PT-gliadin induced zonulin release and transepithelial electrical resistance (TEER) changes in duodenal tissues from celiac disease (CD) patients in remission. Duodenal tissues from CD patients in remission were mounted in the microsnapwell system and exposed to PT-gliadin, either alone or following 15 min preincubation with FZI/0. A. The TEER decrement induced by PT-gliadin (squares) was prevented by pretreatment with FZI/0 $(10 \mu \mathrm{g} / \mathrm{ml})$ (triangles). PD-casein-treated tissues (circle) are shown as negative controls. B. FZI/0 pretreatment (triangles) did not affect the zonulin release by PT-gliadin (squares) $(\mathrm{B}) .{ }^{\star} p<0.02$ compared with PT-gliadin; $n=17$. 

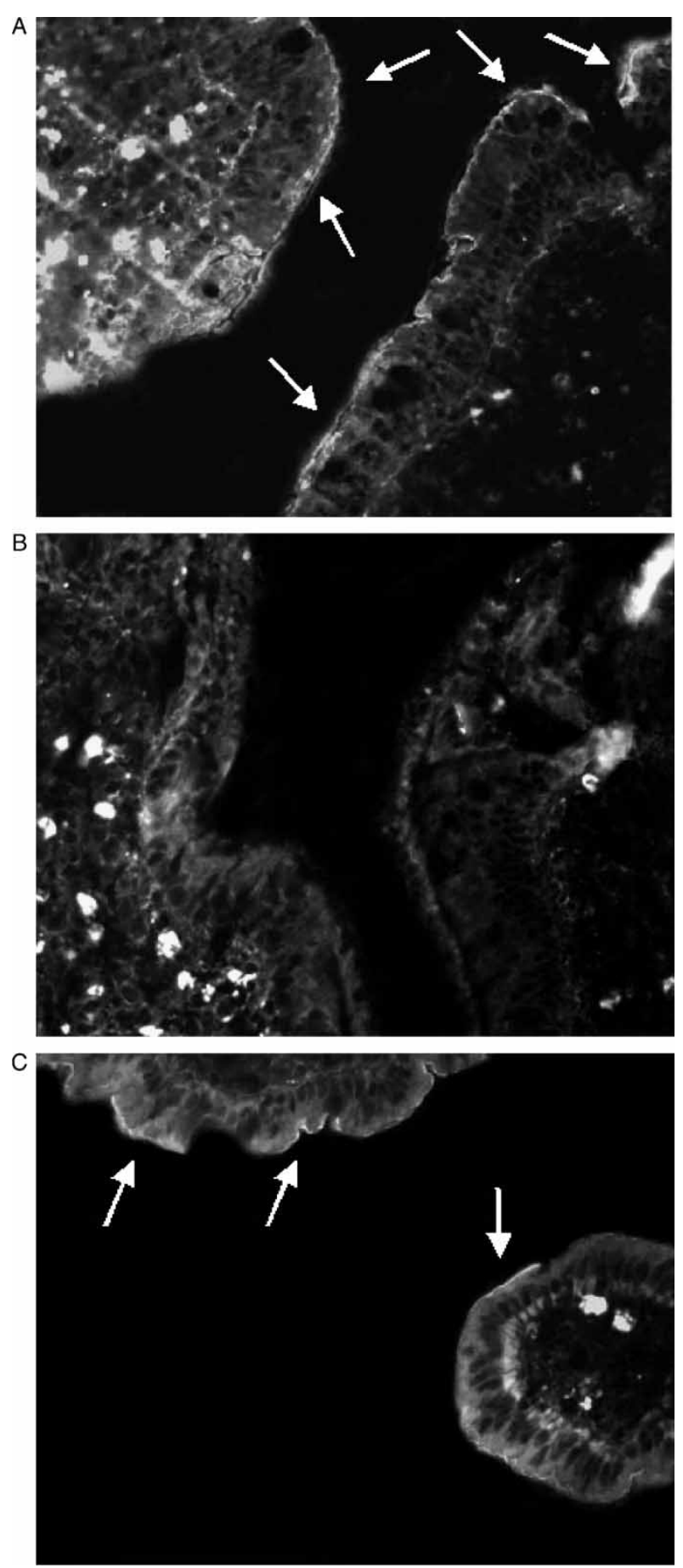

Figure 7. Zonulin surface binding on intestinal biopsies from celiac disease (CD) patients in remission and non-CD patients following PT-gliadin exposure. A. Intestinal biopsies from CD patients in remission exposed to PT-gliadin showed a homogeneous zonulin binding on the mucosal surface (arrows) and an increase in staining in the submucosa. B. No surface staining was observed in tissues exposed to negative control. C. Tissues obtained from non-CD patients and exposed to PT-gliadin also showed zonulin surface staining (arrows) but the binding pattern was patchy. Magnification: $\times 40$.

changes following gliadin-induced zonulin release are not mediated by cytokine production [20].
Chronic exposure. Intestinal tissues obtained from CD patients (both during the acute phase of the disease and in remission following a gluten-free diet) as well as from non-CD patients were immediately processed following their collection for mRNA extraction in order to perform ZO-1 and occludin quantitative gene expression by real-time PCR. Patients during the acute phase of $C D$ showed significant lower expression of both genes compared to non-CD controls (Figure 8). Conversely, CD in remission showed ZO-1 and occludin gene expression levels similar to those observed in non-CD controls (Figure 8).

\section{Discussion}

During the past decade, progress has been made in elucidating the biochemical characteristics of the multiple gluten epitopes and in understanding the activation of the immune system by these immunomodulatory/cytotoxic peptides [25]. Alpha-gliadin, which we tested in this study, is a well-characterized gluten fraction containing several different peptides that are capable of activating the immune response that is seen in CD patients [2]. Despite these advances in understanding the pathogenesis of $C D$, little is known about how gliadin actually gains access to the subepithelial compartment in order to interact with the gut-associated lymphoid tissue (GALT) and stimulate autoimmunity. The enterocyte brush-border membrane has carrier systems (PepT1 and PepT2) that facilitate the transcellular transport of di-/tripeptides, while transport of larger peptides is mainly limited to the paracellular route owing to the physical-chemical characteristics of the cellular phospholipid membrane $[26,27]$. Two, not necessarily mutually exclusive pathways have been proposed to explain the passage of gluten peptides in celiac disease: transcellular transport [28] and paracellular permeability $[12,13]$. While neither pathway has been validated as the definitive locus of entry of immunologically active gliadin fragments into the intestinal submucosa, the following observations suggest that the paracellular pathway is of particular importance in the pathogenesis of CD. The association of increased small intestinal permeability with $\mathrm{CD}$ is well established, and clinical studies have shown that patients with active $\mathrm{CD}$ demonstrate elevated fractional sugar permeability due to increased intestinal paracellular passage of larger probes (disaccharides, such as cellobiose and lactulose) [29]. Abnormal paracellular permeability precedes the development of pathology in an animal model of gluten-sensitive enteropathy [30]. A high proportion of 1 st degree relatives of CD patients have an increased urinary lactulose/mannitol ratio without 
Table I. Occludin, ZO-1, and TNF- $\alpha$ gene expression in both celiac and non-celiac human intestine after acute exposure to gliadin in microsnapwells.

\begin{tabular}{|c|c|c|c|c|c|c|}
\hline & \multicolumn{2}{|c|}{ Occludin $^{\star}$} & \multicolumn{2}{|c|}{$\mathrm{ZO}-1^{\star}$} & \multicolumn{2}{|c|}{$\mathrm{TNF}-\alpha^{?}$} \\
\hline & Controls & CD patients & Controls & $\mathrm{CD}$ patients & Controls & $\mathrm{CD}$ patients \\
\hline $0 \mathrm{~min}$ & $811,635 \pm 9,456$ & $824,681 \pm 12,811$ & $703,293 \pm 12,594$ & $722,166 \pm 17,451$ & $675,847 \pm 13,547$ & $577,746 \pm 11,547$ \\
\hline $5 \mathrm{~min}$ & $784,230 \pm 15,689$ & $772,801 \pm 13,141$ & $692,039 \pm 6,939$ & $755,230 \pm 5,170$ & $668,591 \pm 9,004$ & $573,446 \pm 4,004$ \\
\hline $15 \mathrm{~min}$ & $763,754 \pm 1,633$ & $723,814 \pm 7,603$ & $687,864 \pm 9,697$ & $781,349 \pm 12,451$ & $698,345 \pm 10,251$ & $605,558 \pm 11,840$ \\
\hline $30 \mathrm{~min}$ & $778,654 \pm 3,256$ & $750,404 \pm 4,638$ & $675,847 \pm 4,454$ & $751,349 \pm 10,451$ & $628,213 \pm 12,890$ & $590,974 \pm 11,001$ \\
\hline $60 \mathrm{~min}$ & $766,532 \pm 2,986$ & $735,635 \pm 12,580$ & $690,552 \pm 3,945$ & $748,291 \pm 16,451$ & $648,672 \pm 18,255$ & $593,588 \pm 8,256$ \\
\hline$\Delta(60-0 \mathrm{~min})$ & $-45,103 \pm 9,748$ & $-89,046 \pm 21,110$ & $-12,741 \pm 7,358$ & $+26,125 \pm 13,104$ & $+27,175 \pm 29,884$ & $-15,842 \pm 11,475$ \\
\hline$p$ (vs time 0$)$ & 0.05 & $0.01^{\star \star}$ & NS & NS & NS & NS \\
\hline
\end{tabular}

$\mathrm{N}$ copies $/ 10^{6} \mathrm{GAPDH}$.

${ }^{\star \star} p<0.05$ compared to controls; $n=9$.

developing the disease, suggesting that the increased intestinal permeability and the gliadin-induced intestinal damage are two distinct phenomena [31]. Acute gliadin-challenge studies in celiac patients in remission suggest that one of the immediate consequences of gluten exposure is increased paracellular permeability, occurring within $36 \mathrm{~h}$ [32]. Taken together, these observations suggest that increased permeability is an early event and not just a consequence of chronic intestinal inflammation and parenchymal injury, and that paracellular permeability

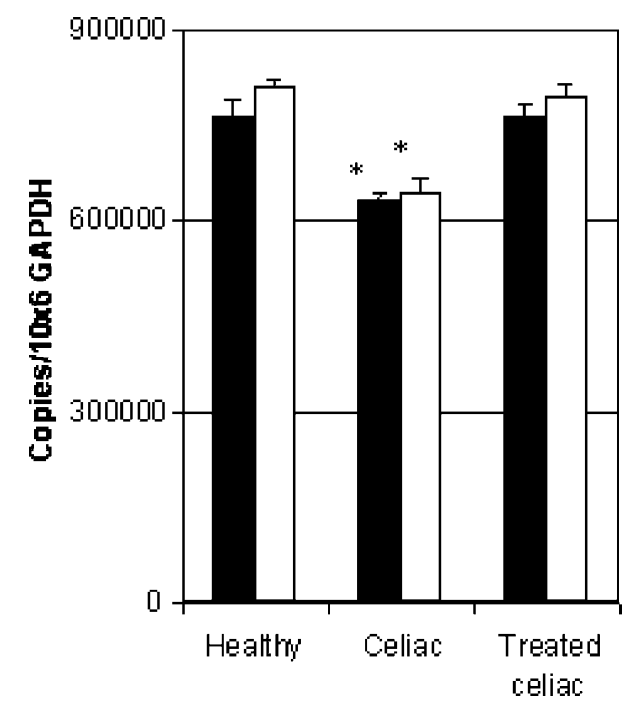

Figure 8. ZO-1 and occludin genes expression following chronic exposure to gliadin. Intestinal tissues obtained from celiac disease (CD) patients (during the acute phase of the disease and also after remission following a gluten-free diet) and from non-CD patients were treated for mRNA extraction immediately following their collection. Quantitative real-time polymerase chain reaction (PCR) using specific primers for ZO-1 (closed bars) and occludin (open bars) genes was performed and the results normalized by the number of GAPDH gene copies. Expression of both ZO-1 and occludin genes was suppressed in $\mathrm{CD}$ patients during the active phase of the disease compared to non-CD controls. Expression of ZO-1 and occludin genes reverted to normal values during the disease remission following a gluten-free diet. ${ }^{\star} p<0.01$ compared to both controls and treated celiacs; $n=9$ for each group. may represent the key route through which gliadin initially gains access into the submucosa.

Zonulin, a pathway that modulates tj competency, is involved in innate immunity [20] and is upregulated in both $\mathrm{CD}$ [12] and type 1 diabetes $[33,34]$. In the $\mathrm{BB} /$ wor rat animal model of type 1 diabetes, increases in zonulin-mediated permeability precede the onset of the autoimmune process by $3-4$ weeks and are prevented by pretreatment with zonulin inhibitor [34]. Therefore, it is conceivable that a similar temporal relationship between exposure to environmental agents, loss of intestinal barrier function, and onset of pathology occurs in CD.

Our results suggest that PT-gliadin peptides induce a series of early mucosal events including zonulin release and binding to receptor-positive cells (Figure 1A and B), cytoskeleton rearrangement (Figure 2), ZO-1 displacement from the junctional complex (Figure 3) and ti disassembly (Figures 4 and 5).

We have previously reported that the interaction of enteric bacteria with intestinal mucosa induces zonulin release as a host-driven innate immunity response [20]. Given the complexity of the cell signaling events and intracellular structures involved in the zonulin system [35], it is not surprising that this pathway may be up-regulated in response to proximal bowel contamination. Intestinal barrier dysfunction, triggered by bacterial infection, has previously been hypothesized as a key factor in several pathological conditions involving the GI tract [36-38]. Increased ti permeability seems to be a common denominator in these diseases and may be responsible for the repeated passage of luminal antigens to the mucosal immune system. The response to this submucosal exposure is dictated by host genetic predisposition either to recognize or misinterpret environmental antigens when these are presented to the GI tract [39]. The results of this 
study suggest that a direct effect of gliadin on the activation of the zonulin system can be proposed as a driver for antigen access to the GALT via the paracellular route.

Recent reports suggest that CD is one of the most common chronic genetic disorders of humankind $[40,41]$. This observation raises an interesting question. Why is a disease with significant morbidity and increased mortality not segregated by genetic evolution, and why does it remains so frequently expressed? One possible explanation is that gluten, a protein introduced in large quantities in the human diet only after the advent of agriculture, activates mechanisms of innate immunity (e.g. zonulin signaling) that are designed to protect against proximal bowel contamination and are too important for human survival to be eliminated. This hypothesis is further supported by recent reports on the role of early dietary introduction of gluten and the increased risk of developing type 1 diabetes $[42,43]$.

This also implies that gliadin should activate the zonulin system irrespective of the genetic predisposition to autoimmunity. Our results obtained on intestinal tissues from both $\mathrm{CD}$ and non-CD patients (Figure 5) support this theory. Nevertheless, zonulin is markedly up-regulated in subjects affected by $C D$, even when treated with a gluten-free diet (Figure 5A). This up-regulation is associated with increased baseline gut permeability (Figure 5B), and an increased amplitude and duration of gluteninduced zonulin release when compared with nonCD intestinal samples. Despite the presence of a measurable zonulin response in both $\mathrm{CD}$ and nonCD subjects, $C D$ patients appear to reach a critical threshold of intestinal permeability upon gliadin exposure that is not reached in non-CD intestinal mucosa (Figure 5). Pretreatment with the zonulin inhibitor FZI/0 prevents the gliadin-induced TEER decrement, confirming that zonulin is the mediator of these gluten-induced changes and possibly paving the way for treatment alternatives to a gluten-free diet.

\section{Acknowledgements}

This study was partially supported by the National Institute of Health, Grants DK-48373 and DK-66630 (A.F.). Sandro Drago and Ramzi El Asmar contributed equally to the execution of this project.

\section{References}

[1] Trier JS. Diagnosis of celiac sprue. Gastroenterology 1998; 115:211-6.

[2] Schuppan D. Current concepts of celiac disease pathogenesis. Gastroenterology 2000;119:234-42.
[3] Sollid LM, Thorsby E. HLA susceptibility genes in celiac disease: genetic mapping and role in pathogenesis. Gastroenterology 1993;105:910-22.

[4] Dieterich W, Ehnis T, Bauer M, Donner P, Volta U, Riecken $\mathrm{EO}$, et al. Identification of tissue transglutaminase as the autoantigen of celiac disease. Nat Med 1997;3:797-801.

[5] Molberg O, McAdam SN, Sollid LM. Role of tissue transglutaminase in celiac disease. J Pediatr Gastroenterol Nutr 2000;30:232-40.

[6] Molberg O, Mcadam SN, Korner R, Quarsten H, Kristiansen C, Madsen L, et al. Tissue transglutaminase selectively modifies gliadin peptides that are recognized by gut-derived T cells in coeliac disease. Nat Med 1998;4:713-7.

[7] Pender SL, Tickle SP, Docherty AJ, Howie D, Wathen NC, MacDonald TT. A major role for matrix metalloproteinases in T cell injury in the gut. J Immunol 1997;158:1582-90.

[8] Fasano A. Modulation of intestinal permeability: an innovative method of oral drug delivery for the treatment of inherited and acquired human diseases. Molec Genet Metab 1998;64:12-8.

[9] Madara JL, Trier JS. Structural abnormalities of jejunal epithelial cell membranes in celiac sprue. Lab Invest 1980; 43:254-61.

[10] Schulzke JD, Bentzel CJ, Schulzke I, Riecken EO, Fromm $M$. Epithelial tight junction structure in the jejunum of children with acute and treated celiac sprue. Pediatr Res 1998;43:435-41.

[11] Wang W, Uzzau S, Goldblum SE, Fasano A. Human zonulin, a potential modulator of intestinal tight junctions. J Cell Sci 2000;113:4435-40.

[12] Fasano A, Not T, Wang W, Uzzau S, Berti I, Tommasini A, et al. Zonulin, a newly discovered modulator of intestinal permeability, and its expression in coeliac disease. Lancet 2000;355:1518-9.

[13] Clemente MG, De Virgiliis S, Kang JS, Macatagney R, Musu MP, Di Pierro MR, et al. Early effects of gliadin on enterocyte intracellular signalling involved in intestinal barrier function. Gut 2003;52:218-23.

[14] Leach L, Firth JA. Structure and permeability of human placental microvasculature. Microsc Res Tech 1997;38:13744.

[15] Madsen KL, Lewis SA, Tavernini MM, Hibbard J, Fedorak $\mathrm{RN}$. Interleukin 10 prevents cytokine-induced disruption of T84 monolayer barrier integrity and limits chloride secretion. Gastroenterology 1997;113:151-9.

[16] De Ritis G, Occorsio P, Auricchio S, Gramenzi F, Morisi G, Silano V. Toxicity of wheat flour proteins and proteinderived peptides for in vitro developing intestine from rat fetus. Pediatr Res 1979;13:1255-61.

[17] Shan L, Molberg O, Parrot I, Hausch F, Filiz F, Gray GM, et al. Structural basis for gluten intolerance in celiac sprue. Science 2002;297:2275-9.

[18] Di Pierro M, Lu R, Uzzau S, Wang W, Margaretten K, Pazzani C, et al. Zonula occludens toxin structure-function analysis. Identification of the fragment biologically active on tight junctions and of the zonulin receptor binding domain. J Biol Chem 2001;276:19160-5.

[19] Fasano A, Uzzau S, Fiore C, Margaretten K. The enterotoxic effect of zonula occludens toxin on rabbit small intestine involves the paracellular pathway. Gastroenterology 1997;112:839-46.

[20] El Asmar R, Panigrahi P, Bamford P, berti I, Not T, Coppa $\mathrm{GV}$, et al. Host-dependent zonulin secretion causes the impairment of the small intestine barrier function after bacterial exposure. Gastroenterology 2002;123:1607-15.

[21] Livak KJ, Flood SJ, Marmaro J, Giusti W, Deetz K. Oligonucleotides with fluorescent dyes at opposite ends 
provide a quenched probe system useful for detecting PCR product and nucleic acid hybridization. PCR Methods Appl 1995;4:357-62.

[22] Uzzau S, Lu R, Wang W, Fiore C, Fasano A. Purification and preliminary characterization of the zonula occludens toxin receptor from human $(\mathrm{CaCo} 2)$ and murine (IEC6) intestinal cell lines. FEMS Microbiol Lett 2001;194:1-5.

[23] Mitic LL, Anderson JM. Molecular architecture of tight junctions. Annu Rev Physiol 1998;60:121-42.

[24] Itoh M, Furuse M, Morita K, Kubota K, Saitou M, Tsukita S. Direct binding of three tight junction-associated MAGUKs, ZO-1, ZO-2, and ZO-3, with the $\mathrm{COOH}$ termini of claudins. J Cell Biol 1999;147:1351-63.

[25] Koning F. The molecular basis of celiac disease. J Mol Recog 2003;16:333-6.

[26] Daniel H. Molecular and integrative physiology of intestinal peptide transport. Annu Rev Physiol 2004;66:361-84.

[27] Walker WA. Antigen handling by the small intestine. Clin Gastroenterol 1986;15:1-20.

[28] Matysiak-Budnik T, Candalh C, Dugave C, Namane A, Cellier C, Cerf-Bensussan, et al. Alterations of the intestinal transport and processing of gliadin peptides in celiac disease. Gastroenterology 2003;125:696-707.

[29] Catassi C, Pierani P, Natalini G, Gabrielli O, Coppa GV, Giorgi PL. Clinical application of a simple HPLC method for the sugar intestinal permeability test. J Pediatr Gastroenterol Nutr 1991;12:209-12.

[30] Hall EJ, Batt RM. Abnormal permeability precedes the development of a gluten sensitive enteropathy in Irish setter dogs. Gut 1991;32:749-53.

[31] van Elburg RM, Uil JJ, Mulder CJ, Heymans HS. Intestinal permeability in patients with celiac disease and relatives of patients with celiac disease. Gut 1993;34:354-7.

[32] Di Cagno R, De Angelis M, Auricchio S, Greco L, Clarke C, De Vincenzi $M$, et al. Sourdough bread made from wheat and nontoxic flours and started with selected lactobacilli is tolerated in celiac sprue patients. Appl Environ Microbiol 2004;70:1088-96.
[33] Sapone A, Watts T, Counts D, Zielke R, Bizzari, Fasano A. Inhibition of the zonulin-dependent increased intestinal permeability prevents the onset of type 1 diabetes in $\mathrm{BB} /$ wor rats. Gastroenterology 2004;126A-518.

[34] Watts T, Berti I, Sapone A, Gerarduzzi T, Not T, Zielke R, et al. Role of the intestinal tight junction modulator zonulin in the pathogenesis of type-I diabetes in BB diabetic prone rats. Proc Natl Acad Sci USA 2005;102:2916-21.

[35] Fasano A, Fiorentini C, Donelli G, Uzzau S, Kaper JB, Margaretten $\mathrm{K}$, et al. Zonula occludens toxin modulates tight junctions through protein kinase C-dependent actin reorganization, in vitro. J Clin Invest 1995;96:710-20.

[36] Fleckenstein JM, Kopecko DJ. Breaching the mucosal barrier by stealth: an emerging pathogenic mechanism for enteroadherent bacterial pathogens. J Clin Invest 2001;107: $27-30$.

[37] Wittig BM, Zeitz M. The gut as an organ of immunology. Int J Colorectal Dis 2003;18:181-7.

[38] Mowat AM. Anatomical basis of tolerance and immunity to intestinal antigens. Nat Rev Immunol 2003;3:331-41.

[39] Fasano A. Pathological and therapeutical implications of macromolecules passage through the tight junction. In: Cereijido M, Anderson J, editors. Tight functions. Boca Raton: CRC Press; 2001. pp 697-722.

[40] Fasano A, Berti I, Gerarduzzi T, Not T, Colletti RB, Drago $\mathrm{S}$, et al. Prevalence of celiac disease in at-risk and not-at-risk groups in the United States: a large multicenter study. Arch Intern Med 2003;163:286-92.

[41] Maki M, Mustalahti K, Kokkonen J, Kulmala P, Haapalahti M, Karttunen TJ, et al. Prevalence of celiac disease among children in Finland. N Engl J Med 2003;348:2517-24.

[42] Norris JM, Barriga K, Klingensmith G, Hoffman M, Eisenbarth GS, Erlich HA, et al. Timing of initial cereal exposure in infancy and risk of islet autoimmunity. JAMA 2003;290:1713-20.

[43] Ziegler AG, Schmid S, Huber D, Hummel M, Bonifacio E. Early infant feeding and risk of developing type 1 diabetesassociated autoantibodies. JAMA 2003;290:1721-8. 